\title{
Research
}

\section{Comparing performance among male and female candidates in sex-specific clinical knowledge in the MRCGP}

\begin{abstract}
\section{Background}

Patients often seek doctors of the same sex, particularly for sex-specific complaints and also because of a perception that doctors have greater knowledge of complaints relating to their own sex. Few studies have investigated differences in knowledge by sex of candidate on sex-specific questions in medical examinations.

\section{Aim}

The aim was to compare the performance of males and females in sex-specific questions in a 200 -item computer-based applied knowledge test for licensing UK GPs.
\end{abstract}

\section{Design and setting}

A cross-sectional design using routinely collected performance and demographic data from the first three versions of the Applied Knowledge Test, MRCGP, UK

\section{Method}

Questions were classified as female specific, male specific, or sex neutral. The performance of males and females was analysed using multiple analysis of covariance after adjusting for sex-neutral score and demographic confounders.

\section{Results}

Data were included from 3627 candidates. After adjusting for sex-neutral score, age, time since qualification, year of speciality training, ethnicity, and country of primary medical qualification, there were differences in performance in sexspecific questions. Males performed worse than females on female-specific questions $(-4.2 \%$, $95 \%$ confidence interval $[\mathrm{Cl}]=-5.7$ to -2.6 ) but did not perform significantly better than females on male-specific questions $10.3 \%, 95 \% \mathrm{Cl}=-2.6$ to $3.2 \%$

\section{Conclusion}

There was evidence of better performance by females in female-specific questions but this was small relative to the size of the test. Differential performance of males and females in sexspecific questions in a licensing examination may have implications for vocational and postqualification general practice training

\section{Keywords}

assessment; general practice; learning; medical education; primary health care; sex.

\section{INTRODUCTION}

Patients seeking medical advice in a primary care setting can usually elect to consult any available GP working at their practice. Studies have shown that approximately a third of patients in general practice would rather see a doctor of their own sex, while the remainder have no preference." The term 'sex' is used rather than 'gender' in this article because 'sex' refers to the biological and physiological characteristics that define males and females, whereas 'gender' refers to the socially constructed roles, behaviours, activities, and attributes that a given society considers appropriate for males and females. ${ }^{2}$

Sex preferences in relation to choice of doctor - that is, preference for a male or female doctor - are more evident in specialties such as general practice, or those involving intimate or psychosocial problems, 3,4 than in more technical specialities such as anaesthetics or surgery. However, a minority of patients express a preference for a doctor of the same sex whether they are seeking care in technical specialities 6,7 or in general practice, which extends beyond the management of sexspecific problems. ${ }^{8}$

The reasons for predilection for a doctor of the same sex are likely to be complex: as well as the perceived practical ease of being

AN Siriwardena, MMEdSci, PhD, FRCGP professor of primary and prehospital healthcare ZB Asghar, BSC(Hons), MSc, PhD, research

fellow, School of Health and Social Care, University of Lincoln. B Irish, BSc, MMEd, FRCGP director of GP education, Academic Centre, Frenchay Hospital, Bristol. H Dixon, BSc, DRCOG, EdD, FRCGP, medical director, North East Primary Care Services Agency, Sunderland. P Milne, PhD, FRCGP, senior lecturer in general practice, University of Central Lancashire, Preston. C Neden, MA, FRCP, FRCGP, GP principal, East Cliff Practice, Ramsgate. J Richardson, MRCP. FRCGP, GP principal, Island Health, London. C Blow, FRCP, FRCGP, DipDerm, DRCOG, applied examined by someone of the same sex these may include beliefs about, and preferences for, knowledge, competence, and interpersonal skills. ${ }^{9,10}$ Stereotyping of physician attributes by patients may extend to the belief that a doctor of the same sex as the patient will have a significantly greater knowledge of clinical problems specific to that sex. Female patients commonly consult their GP with sex-specific issues, such as breast or gynaecological disease, and male patients may consult with problems such as erectile dysfunction or prostatic disease. Although female doctors are known to perform better overall in high-stakes medical examinations ${ }^{11,12}$ and in sex-specific domains, for example in obstetrics and gynaecology, ${ }^{13}$ or other areas such as paediatrics, 14,15 there is limited published evidence showing differences between male and female GPs in knowledge of sex-specific clinical areas at licensure. Such differences may have important implications for general practice training.

The Membership of the Royal College of General Practitioners (MRCGP)16 is the licensing examination for UK-trained family doctors that certifies their fitness for independent practice. This provides a Certificate of Completion of Training (CCT) in general practice and entry to the General Practice Register of the General Medical

knowledge test clinical lead MRCGP examination Stonehaven Medical Practice, Stonehaven. Address for correspondence

A Niroshan Siriwardena, School of Health and Social Care, College of Social Science, University of Lincoln, Lincoln, LN6 7TS.

E-mail: nsiriwardenadlincoln.ac.uk

Submitted: 30 October 2011; Editor's response: 23 November 2011; final acceptance: 16 January 2012

OBritish Journal of General Practice

This is the full-length article (published online 28 May 2012) of an abridged version published in print. Cite this article as: Br J Gen Pract 2012; DOI: 10.3399/bjgp12X649142. 


\section{How this fits in}

Males and females show differences in performance in medical examinations, including tests that assess sex-specific issues such as obstetrics and gynaecology. This study demonstrates that there was significantly better performance in females compared with males regarding knowledge on female health in a general practice licensing examination. Factors that determine variations in performance for different question types deserve further investigation.

Council. ${ }^{17}$ The assessment includes three components - the Applied Knowledge Test (AKT), a clinical skills assessment, and workplace-based assessments - which, together, assess the curriculum for specialty training for general practice. ${ }^{18}$

The AKT is a 3-hour, 200-item multiplechoice test, which assesses knowledge of clinical medicine (80\%), evidence-based medicine $(10 \%)$, and administrative issues $(10 \%)$ relevant to UK general practice; it uses the single-best answer and extended modified-question formats. The test is constructed by a group of GPs with expertise in item writing; individual question performance is analysed using classical test theory, which enables refinement of poorly performing questions by this group. ${ }^{19}$ Each AKT examination includes a number of sexspecific questions, that is, items on female and male health, which sample across the curriculum.

The aim of this study was to compare differences in the knowledge of male and female candidates with regard to sex-specific questions tested in the AKT.

\section{METHOD}

A cross-sectional design was employed using routinely collected performance and demographic data from the first three versions of the AKT. Questions testing knowledge in the first three AKT papers (AKT1, AKT2, and AKT3) taken by candidates over a 1-year period were classified independently by each of the authors as female specific (that is, relating to female health problems), male specific, or sex neutral. Box 1 gives an example of a femalespecific question. Inter-rater agreement was assessed using Cohen's kappa: the value of kappa for any two sets of coders was $\geq 0.75$. In the case of disagreement, the item was assigned according to the majority view. The three examinations each comprising 200 questions included seven, seven, and six male-specific questions and 19, 14, and 20 female-specific questions respectively.

Examination scores and demographic data, including candidate sex, age, year of qualification, stage of training, ethnic group, and place of primary medical qualification, were obtained from the MRCGP examination department for each examination candidate. Ethical approval was granted by the University of Lincoln Research Ethics Committee. All data were anonymised.

The association of candidate sex with scores for sex-specific questions was determined using multivariate analysis of covariance, correcting for other confounders including sex-neutral test score, years since qualification, stage of general practice specialty training, ethnicity, and country of primary medical qualification.

Categorical variables were created from continuous variables using cut-off points created as close as possible to quartiles but with whole years. Categories were established for age (25-29 years, 30-31 years, 32-35 years, and 36-70 years), years since qualification $10-4$ years, 5-6 years, 7-8 years, 9-39 years), stage of general practice specialty training (Speciality Year 1, Speciality Year 2, Speciality Year 3, fully trained, or summative assessment), ethnicity Iwhite, Asian, African-Caribbean, mixed, other, and unknown), and country of primary medical qualification (UK; European Union and Russia; US, Canada and Oceania; Africa; and South Asia).

A quantile-quantile $(Q-Q)$ plot of residuals was performed to validate model fitness. All interactions were fitted and non-significant effects dropped after applying a Bonferroni correction because of multiple comparisons.

\section{RESULTS}

The analysis included examination data from 3627 candidates, $45.5 \%$ of whom were males and $54.5 \%$ of whom were females. Candidates characteristics are detailed in Table 1. The mean female-specific score was higher for females (83.2\%; standard deviation [SD] 9.8\%) compared with males $(77.1 \%$; SD 11.7\%; $P<0.001$ ). The mean male-specific score was not significantly different for males (64.1\%; SD 20.2\%) and females (65.0\%; SD 19.6\%; $P=0.19$ ) (Table 2).

Males performed worse than females on female-specific questions $(-4.2 \%, 95 \% \mathrm{Cl}=$ -5.7 to -2.6$)$ after correcting for younger age, white ethnicity, later stage of training, and overall performance expressed as sexneutral score that were all significant predictors for higher scores (Table 3). The Q$Q$ plot suggested a good statistical model fit (Figure 1). Plots of $P$-values showed significantly better female-specific 
Table 1. Summary characteristics of 3627 female and male candidates

\begin{tabular}{|c|c|c|c|}
\hline & Female, $n(\%)$ & Male, $n(\%)$ & Total \\
\hline \multicolumn{4}{|l|}{ Age group, years } \\
\hline $25-29$ & $840(46.1)$ & 490 (32.3) & 1330 \\
\hline $30-31$ & $592(32.5)$ & $594(39.1)$ & 1186 \\
\hline $32-35$ & $231(12.7)$ & $214(14.1)$ & 445 \\
\hline $36-70$ & $158(8.7)$ & $221(14.6)$ & 379 \\
\hline Total & $1821(100.0)$ & $1519(100.0)$ & 3340 \\
\hline \multicolumn{4}{|l|}{ Years since qualification } \\
\hline $0-4$ & $14(0.9)$ & $9(0.7)$ & 23 \\
\hline $5-6$ & $1125(72.5)$ & 752 (61.3) & 1877 \\
\hline $7-8$ & $279(18.0)$ & 305 (24.9) & 584 \\
\hline $9-39$ & $134(8.6)$ & $161(13.1)$ & 295 \\
\hline Total & $1552(100.0)$ & $1227(100.0)$ & 2779 \\
\hline \multicolumn{4}{|l|}{ Stage of training } \\
\hline Speciality Year 1 & $30(1.6)$ & $26(1.7)$ & 56 \\
\hline Speciality Year 2 & $282(14.9)$ & $236(15.1)$ & 518 \\
\hline Speciality Year 3 & $1266(66.7)$ & 966 (61.8) & 2232 \\
\hline Fully trained & $320(16.9)$ & $335(21.4)$ & 655 \\
\hline Total & $1898(100.0)$ & 1563 (100.0) & 3461 \\
\hline \multicolumn{4}{|l|}{ Ethnic group } \\
\hline White & $1077(56.4)$ & $534(33.6)$ & 1611 \\
\hline Asian & $679(35.6)$ & $863(54.4)$ & 1542 \\
\hline African-Caribbean & 62 (3.3) & $85(5.4)$ & 147 \\
\hline Mixed & $31(1.6)$ & $27(1.7)$ & 58 \\
\hline Other & $58(3.0)$ & 78 (4.9) & 136 \\
\hline Unknown & $49(2.6)$ & $31(2.0)$ & 80 \\
\hline Total & $1907(100.0)$ & $1587(100.0)$ & 3494 \\
\hline \multicolumn{4}{|c|}{ Place of primary medical qualification } \\
\hline Africa & 56 (2.8) & $88(5.4)$ & 144 \\
\hline EU and Russia & 135 (6.8) & $114(6.9)$ & 249 \\
\hline South Asia & $410(20.7)$ & 571 (34.8) & 981 \\
\hline UK & 1263 (63.7) & 763 (46.4) & 2026 \\
\hline US, Canada, and Oceania & $37(1.9)$ & $34(2.1)$ & 71 \\
\hline Other & $83(4.2)$ & $73(4.4)$ & 156 \\
\hline Total & $1984(100.1)$ & $1643(100.0)$ & 3627 \\
\hline
\end{tabular}

Totals less than 3627 indicate missing data for these variables. EU = European Union.

Table 2. Performance of female and male candidates in sex-related questions

\begin{tabular}{lccccccc} 
& \multicolumn{3}{c}{ Females $(\%)$} & & Males $(\%)$ & Total \\
\cline { 2 - 8 } & $\boldsymbol{n}$ & Mean & SD & $\boldsymbol{n}$ & Mean & SD & $\boldsymbol{n}$ \\
\hline Total score & 1984 & 76.4 & 7.7 & 1643 & 73.4 & 8.1 & 3627 \\
\hline Sex-neutral score & 1984 & 74.0 & 8.3 & 1643 & 70.8 & 8.7 & 3627 \\
\hline Male-specific score & 1984 & 65.0 & 19.6 & 1643 & 64.1 & 20.2 & 3627 \\
\hline Female-specific score & 1984 & 83.2 & 9.8 & 1643 & 77.1 & 11.7 & 3627 \\
\hline
\end{tabular}

$S D=$ standard deviation

Table 3. Regression analysis (ANCOVA) for variables predicting female-specific examination score

Female-specific question score:

demographic and background factors Coefficient Standard error $\boldsymbol{P}$-value $(95 \% \mathrm{CI})$

\begin{tabular}{lccc}
\hline Sex & -4.2 & 0.8 & $<0.001(-5.7$ to -2.6$)$ \\
\hline Age & -0.3 & 0.1 & $<0.001(-0.6$ to -0.1$)$ \\
\hline Ethnicity & 0.6 & 0.1 & $<0.001(0.3$ to 0.9$)$ \\
\hline Sex-neutral score & -2.4 & 0.1 & $<0.001(-2.6$ to -2.1$)$ \\
\hline Stage of training & 2.0 & 0.3 & $<0.001(1.4$ to 2.5$)$ \\
\hline
\end{tabular}

ANCOVA = analysis of covariance. examination scores for female compared to male candidates after applying a Bonferroni correction. For male-specific question scores, males did not perform significantly better than females $10.3 \%, 95 \% \mathrm{Cl}=-2.6$ to $3.2 \%$ ) after correcting for sex-neutral score and demographic factors (Table 4).

\section{DISCUSSION \\ Summary}

This is the first study investigating differences in knowledge by sex of candidate on sexspecific questions in a medical licensing examination for general practice. These results showed that, on average, males scored worse than females on femalespecific questions after controlling for other significant predictors for differences in scores. The actual difference in test performance was small due to the small number of female sex-specific questions, which comprised only $9 \%$ of questions across the three examinations. There were even fewer male-specific questions compared with female-specific questions over the three tests $(20 / 600$ [3\%] versus $53 / 600$ [9\%]) which may have partly accounted for the lack of difference in male doctor performance for male-specific questions.

In contrast, males did not perform significantly differently from females in male sex-specific questions; this showed that females were just as knowledgeable about male health issues as males.

\section{Strengths and limitations}

A large number of candidates were included and the recording rates of demographic variables were high. This investigation was limited to a single knowledge test format in general practice in one developed country and showed differences in cognitive knowledge, rather than competence, performance, or psychomotor skills; the results, therefore, cannot be extrapolated to knowledge tests in other specialties or other countries. Potential confounders in the analysis were accounted for. An alternative means of investigating sex bias in responses would have been to conduct a differential item functioning analysis using item response theory. ${ }^{20}$

\section{Comparison with existing literature}

This study focused on knowledge rather than performance or clinical behaviour. Previous studies of examination performance have shown differences according to sex of candidate at different stages in trainees medical education. ${ }^{21}$ This contrasts with some other studies, however, that have not 


\section{Table 4. Regression analysis (ANCOVA) for variables predicting male- specific examination score}

\begin{tabular}{lccc}
$\begin{array}{l}\text { Male-specific question score: } \\
\text { demographic and background factors }\end{array}$ & Coefficient & Standard error & $\boldsymbol{P}$-value (95\% CI) \\
\hline Sex & 0.3 & 1.5 & 0.8 (-2.6 to 3.2) \\
\hline Age & 0.0 & 0.2 & $1.0(-0.4$ to 0.4) \\
\hline Ethnicity & 1.1 & 0.3 & $<0.001(0.5$ to 1.6$)$ \\
\hline Sex-neutral score & -2.9 & 0.2 & $<0.001(-3.3$ to -2.5$)$ \\
\hline Stage of training & 2.3 & 0.5 & $<0.001(1.3$ to 3.4) \\
\hline ANCOVA = analysis of covariance. & & &
\end{tabular}

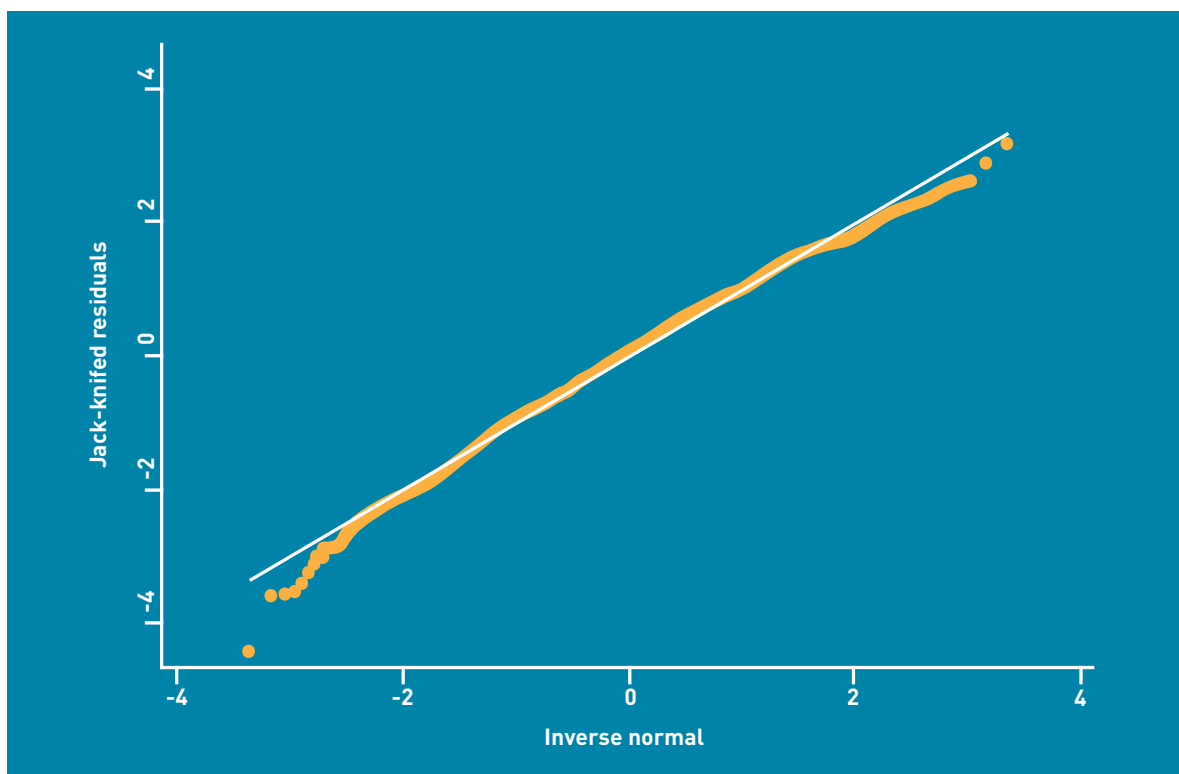

Figure 1. The quantile-quantile plot of residuals of Ancova model.

found sex differences in specific skills and behaviours, such as sharing management options.22

\section{Ethical approval}

This study was approved by the ethics committee of the Lincoln School of Health and Social Care at the University of Lincoln.

\section{Provenance}

Freely submitted; externally peer reviewed.

\section{Competing interests}

All authors, aside from Bill Irish and Zahid Asghar, are members of the panel of examiners of the Royal College of General Practitioners and members of the Applied Knowledge Test (AKT) Development Group. The authors state there are no other competing interests.

\section{Acknowledegments}

We thank the members of the AKT Development Group and MRCGP Research Reference Group who advised and commented on this study.

\section{Discuss this article}

Contribute and read comments about this article on the Discussion Forum: http://www.rcgp.org.uk/bjgp-discuss
These differences, when they are present, may be partly due to the different educational experiences of male and female doctors. For example, during training, women doctors are significant more likely than men to see patients of the same sex, whereas the converse is not true, ${ }^{23}$ particularly for female problems or intimate examinations ${ }^{24}$ - these differences in experience are likely to be increased when they have a preceptor of the same sex. ${ }^{25}$ This greater exposure to sexspecific problems, rather than simply a greater interest in problems relating to their own sex, may increase motivation among female trainees to learn more about female health issues.

Differences in knowledge may partly explain sex differences in clinical behaviour, for example in test ordering, ${ }^{26}$ sexual-history taking, ${ }^{27}$ or specific healthcare interventions, such as screening ${ }^{14}$ However, an important finding from previous research is that performance is related to clinical skills rather than a doctor's sex per se - male doctors providing routine gynaecology care ${ }^{28}$ or working in centres of excellence for female health also received high ratings from female patients. ${ }^{29}$

\section{Implications for practice and research}

In assessing clinical knowledge, it is important that sex-specific knowledge is tested. It is also important to consider the appropriate educational response to differences, albeit small, in sex-specific clinical knowledge between males and female doctors; this has been demonstrated in this study.

Increased awareness of disparities in knowledge enables these to be identified and addressed through curriculum planning and organising learning experiences appropriately. Although this is already being done in some settings in relation to practical skills, such as intimate examinations, ${ }^{30}$ and may go some way to reducing sex bias in the clinical behaviour of doctors. ${ }^{31}$ the current findings raise issues around the assimilation of sex-specific knowledge in clinical practice. For example, opportunities for trainees to spend some time with trainers of the opposite sex may be helpful. ${ }^{25}$

Current trends suggest that female doctors are seeing increasing numbers of female patients, ${ }^{32}$ which will mean that many are likely to be more proficient than male doctors in dealing with female issues during independent clinical practice Although it might be expected that males doctors are more likely to see male patients for problems such as erectile dysfunction and prostatic disease, this is not the case for trainees, a finding which may be partly explained by the low consultation rates for these conditions. ${ }^{23}$

Despite these changing working patterns and patterns of consulting behaviour among patients, training should ensure that patients consulting doctors of the opposite sex for sex-specific problems will not be disadvantaged in terms of the quality of care provided.

It is important to note that patient preferences for the sex of their doctor are more often related to interpersonal skills, clinical behaviour, and expertise, rather than sex alone. ${ }^{10}$ These behaviours and competencies may become an important area for professional development when it comes to extending future general practice training. ${ }^{33}$ Further evaluation of performance in sex-specific questions in other generalist or specialist examinations and the reasons for such differences warrants further study. 


\section{REFERENCES}

1. Fennema K, Meyer DL, Owen N. Sex of physician: patients' preferences and stereotypes. J Fam Pract 1990; 30(4): 441-446.

2. World Health Organization. What do we mean by 'sex' and 'gender'? in Gender, Women and Health. Geneva: WHO, 2011

http://www.who.int/gender/whatisgender/en/ laccessed 28 Mar 2012).

3. Haar E, Halitsky V, Stricker G. Factors related to the preference for a female gynecologist. Med Care 1975; 13(9): 782-790.

4. Carrejo MH, Balla DJ, Tan RS. Preference for gender of health care provider in management of erectile dysfunction. Int J Impot Res 2007; 19(5): 474-479.

5. Kerssens JJ, Bensing JM, Andela MG. Patient preference for genders of health professionals. Soc Sci Med 1997; 44(10): 1531-1540.

6. Menees SB, Inadomi JM, Korsnes S, Elta GH. Women patients' preference for women physicians is a barrier to colon cancer screening. Gastrointest Endosc 2005; 62(2): 219-223.

7. Tempest HV, Vowler S, Simpson A. Patients' preference for gender of urologist. Int J Clin Pract 2005; 59(5): 526-528.

8. Graffy J. Patient choice in a practice with men and women general practitioners. Br J Gen Pract 1990; 40(330): 13-15.

9. Shah R, Ogden J. 'What's in a face?' The role of doctor ethnicity, age and gender in the formation of patients' judgements: an experimental study. Patient Educ Couns 2006; 60(2): 136-141.

10. Mavis B, Vasilenko P, Schnuth R, et al. Female patients' preferences related to interpersonal communications, clinical competence, and gender when selecting a physician. Acad Med 2005; 80(12): 1159-1165.

11. Wiskin CM, Allan TF, Skelton JR. Gender as a variable in the assessment of final year degree-level communication skills. Med Educ 2004; 38(2): 129-137.

12. Cuddy MM, Swanson DB, Dillon GF, et al. A multilevel analysis of the relationships between selected examinee characteristics and United States Medical Licensing Examination Step 2 Clinical Knowledge performance: revisiting old findings and asking new questions. Acad Med 2006; 81(10 Suppl): S103-S107.

13. Bienstock JL, Martin S, Tzou W, Fox HE. Medical students' gender is a predictor of success in the obstetrics and gynecology basic clerkship. Teach Learn Med 2002; 14(4): 240-243

14. Henderson JT, Weisman CS. Physician gender effects on preventive screening and counseling: an analysis of male and female patients' health care experiences. Med Care 2001; 39(12): 1281-1292.

15. McDonough CM, Horgan A, Codd MB, Casey PR. Gender differences in the results of the final medical examination at University College Dublin. Med Educ 2000; 34(1): 30-34

16. Royal College of General Practitioners. Examination for membership (MRCGP) regulations for 2008. London: RCGP, 2008.
17. Royal College of General Practitioners. nMRCGP: the CCT and new Membership Assessment. London: RCGP, 2008. http://uww.rcgpcurriculum.org.uk/nmrgcp.aspx laccessed 28 Mar 2012).

18. Riley B, Haynes J, Field S. The condensed curriculum guide for GP training and the new MRCGP. London: RCGP, 2007.

19. Haertal EH. Reliability. In: Brennan RL (ed.). Educational measurement. 4th edn. Westport, CN. American Council on Education/Praeger, 2006.

20. Camilli G. Test fairness. In: Brennan RL (ed.). Educational measurement. 4th edn. Westport, CN. American Council on Education/Praeger, 2006.

21. Pritchard DJ. Effects of sex and alphabetical listing on examination performance of medical students. Med Educ 1988; 22(3): 205-210.

22. Siriwardena AN, Edwards AG, Campion $P$, et al. Involve the patient and pass the MRCGP: investigating shared decision making in a consulting skills examination using a validated instrument. Br J Gen Pract 2006; 56(532): 857-862.

23. De Jong J, Visser MRM, Mohrs J, Waard MW. Opening the black box: the patient mix of GP trainees. Br J Gen Pract 2011; 61(591): e650-e657.

24. Wollstadt LJ, Gravdal J, Glasser M. Gender and the educational experience in a primary care training setting. Fam Med 1990; 22(3): 210-214

25. Levy BT, Merchant ML. Differences in clinical experiences based on gender of third-year medical students in a required family medicine preceptorship. Acad Med 2002; 77(12 pt 1): 1241-1246.

26. Sood R, Sood A, Ghosh AK. Non-evidence-based variables affecting physicians test-ordering tendencies: a systematic review. Neth J Med 2007; 65(5): 167-177.

27. Burd ID, Nevadunsky N, Bachmann G. Impact of physician gender on sexual history taking in a multispecialty practice. J Sex Med 2006; 3(2): 194-200.

28. Bean-Mayberry BA, Chang CC, McNeil MA, Scholle SH. Ensuring high-quality primary care for women: predictors of success. Womens Health Issues 2006; 16(1): $22-29$.

29. Henderson JT, Hudson SS, Weisman CS, Anderson RT. The role of physician gender in the evaluation of the National Centers of Excellence in Women's Health: test of an alternate hypothesis. Womens Health Issues 2004; 14(4): 130-139

30. Hendrickx K, De Winter BY, Wyndaele JJ, et al. Intimate examination teaching with volunteers: implementation and assessment at the University of Antwerp. Patient Educ Couns 2006; 63(1-2): 47-54.

31. Hamberg K, Risberg G, Johansson EE. Male and female physicians show different patterns of gender bias: a paper-case study of management of irritable bowel syndrome. Scand J Public Health 2004; 32(2): 144-152.

32. Fang MC, McCarthy EP, Singer DE. Are patients more likely to see physicians of the same sex? Recent national trends in primary care medicine. Am J Med 2004; 117(8): $575-581$.

33. Kramer AW, Düsman $\mathrm{H}$, Tan LH, et al. Effect of extension of postgraduate training in general practice on the acquisition of knowledge of trainees. Fam Pract 2003; 20(2): 207-212. 